$\begin{array}{ccccccc}t & \theta_{o} & \theta_{c} & \rho_{o} & \rho_{c} & \theta_{o}-\theta_{c} & \rho_{o}-\rho_{c} \\ 1881.53 & 148.1 & 148.8 & 1 \|_{31} & 1.33 & -0.7 & -0.02 \\ 1889.42 & 130.1 & 132.7 & 0.95 & 0.97 & -2.6 & -0.02 \\ 1890.37 & 131.5 & 129.7 & 0.81 & 0.91 & +1.8 & -0.10 \\ 1891.33 & 125.7 & 126.4 & 0.78 & 0.85 & -0.7 & -0.07 \\ 1892.41 & 119.9 & 122.2 & 0.62 & 0.78 & -2.3 & -0.16 \\ 1894.19 & 102.7 & 112.8 & 0.58 & 0.66 & -10.1 & -0.08\end{array}$

St. Pétersbourg, 1908 Octobre.

\begin{tabular}{rcccccc}
\multicolumn{1}{c}{$t$} & \multicolumn{1}{c}{$\theta_{o}$} & $\theta_{c}$ & $\rho_{o}$ & $\rho_{c}$ & $\theta_{o}-\theta_{c}$ & $\rho_{o}-\rho_{c}$ \\
1898.70 & 79.7 & 68.3 & 0.47 & 0.44 & +11.4 & +0.03 \\
1899.71 & 44.1 & 53.5 & 0.59 & 0.44 & -9.4 & +0.15 \\
1901.37 & $354 \pm$ & 32.0 & $0.3 \pm$ & - & $(-38.0)$ & - \\
.53 & 28.6 & 30.3 & $0.5 \pm$ & - & -1.7 & - \\
.54 & $338 \pm$ & 30.1 & - & - & $(-52.1)$ & - \\
1905.45 & 357.7 & 359.1 & 0.89 & 0.72 & -1.4 & +0.17
\end{tabular}

I. Balanovsky.

\title{
Elemente und Ephemeride des Planeten (652) Jubilatrix.
}

Der Planet wurde am 4. November rgo7 von Palisa in Wien entdeckt und von diesem bis zum 28 . Januar 1908 verfolgt (A.N. 4257). Auf Grund der Beobachtungen von Nov. 4, Dez. I 3 und Jan. 5 rechnete Palisa eine Bahn (A.N. 4243), welche bereits recht gut die Beobachtungen darstellte. Diese provisorischen Elemente sind för die folgende Bahn-

Epoche 1907 Nov. 4.5 M. Z. Berlin.

$$
\begin{aligned}
& M=43^{\circ} 0^{\circ} 32^{\prime \prime} 1 \\
& \omega=27433 \quad 0.7 \text { ) } \\
& \delta=861529.2 \\
& i=1543 \text { 11.0 } \\
& \varphi=7 \text { I } 49.8 \\
& \mu=869.682 \\
& \log a=0.407097 \\
& m_{0}=13.9 \quad g=10^{\mathrm{m}} \cdot 9
\end{aligned}
$$

bestimmung benutzt worden. Hierbei wurden die beiden Beobachtungen vom 4. November und die Beobachtung des 5. November zu einem Normalort vereinigt. Als zweiter und dritter Ort dienten die Beobachtungen des 1 3. Dezember 1907

\begin{tabular}{|c|c|c|c|c|}
\hline 1909 & \multicolumn{2}{|c|}{$\alpha 1909.0$} & \multicolumn{2}{|c|}{$\delta 1909.0$} \\
\hline Jan. I4 & $12^{\mathrm{h}}$ & $6^{m} 6^{s}$ & $+19^{\circ}$ & $59: 4$ \\
\hline 16 & & $65^{1}$ & 20 & 13.2 \\
\hline 18 & & 79 & 20 & $27 \cdot 5$ \\
\hline 20 & & 721 & 20 & 42.4 \\
\hline 22 & & 727 & 20 & 57.9 \\
\hline 24 & & 726 & 21 & 13.9 \\
\hline 26 & & $7 \quad 19$ & $2 I$ & 30.5 \\
\hline 28 & & 76 & 2 I & 47.5 \\
\hline $3 c$ & & 646 & 22 & 4.9 \\
\hline Febr. & & 620 & 22 & 22.7 \\
\hline 3 & & $\begin{array}{ll}5 & 47\end{array}$ & 22 & 40.7 \\
\hline 5 & & & 22 & 59.0 \\
\hline 7 & & 423 & 23 & I 7.5 \\
\hline 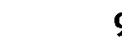 & & 332 & 23 & 36.2 \\
\hline I & & 234 & 23 & 54.9 \\
\hline 13 & & I 30 & 24 & 13.6 \\
\hline I & 12 & 021 & 24 & 32.1 \\
\hline 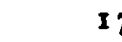 & I I 5 & 596 & 24 & 50.5 \\
\hline 10 & & 5746 & +25 & 8.8 \\
\hline
\end{tabular}
und 28. Januar 1908. Die Rechnung fübrte zu folgenden, von den Palisaschen Resultaten nur wenig abweichenden Elementen:

\begin{tabular}{|c|c|c|c|c|c|}
\hline \multirow[b]{2}{*}{1909} & \multicolumn{3}{|c|}{$M-4 \mu$} & \multicolumn{2}{|c|}{$M$} \\
\hline & $\alpha(1909.0)$ & $8(1909.0)$ & $\log \Delta$ & $\alpha(1909.0)$ & $8(1909.0)$ \\
\hline Jan. 22.5 & $12^{\mathrm{h}} 3^{\mathrm{m}} 40^{\mathrm{s}}$ & $+21^{\circ} 23 !$ & 0.3285 & $12^{\mathrm{h}} 7^{\mathrm{m}} 27^{\mathrm{s}}$ & $+20^{\circ} 57: 9$ \\
\hline Febr. 19.5 & I I 5316 & +2536.5 & 0.2884 & 115746 & +25 \\
\hline Mărz 1 9.5 & 112833 & +2843.1 & 0.2903 & $1133 \quad$ I 8 & +2819.1 \\
\hline
\end{tabular}

Die heliozentrischen Äquatorkoordinaten für 1909.0 berechnen sich aus:

$$
\begin{aligned}
& x=\left[9.9835^{2}\right] r \cdot \sin \left(v+90^{\circ} 41^{\prime} 36^{\prime \prime}\right) \\
& y=[9.96231] r \cdot \sin (v+74257) \\
& z=[9.68316] r \cdot \sin (v+33 \circ \circ 34)
\end{aligned}
$$

Ephemeride für Mittl. Berl. Mitternacht.

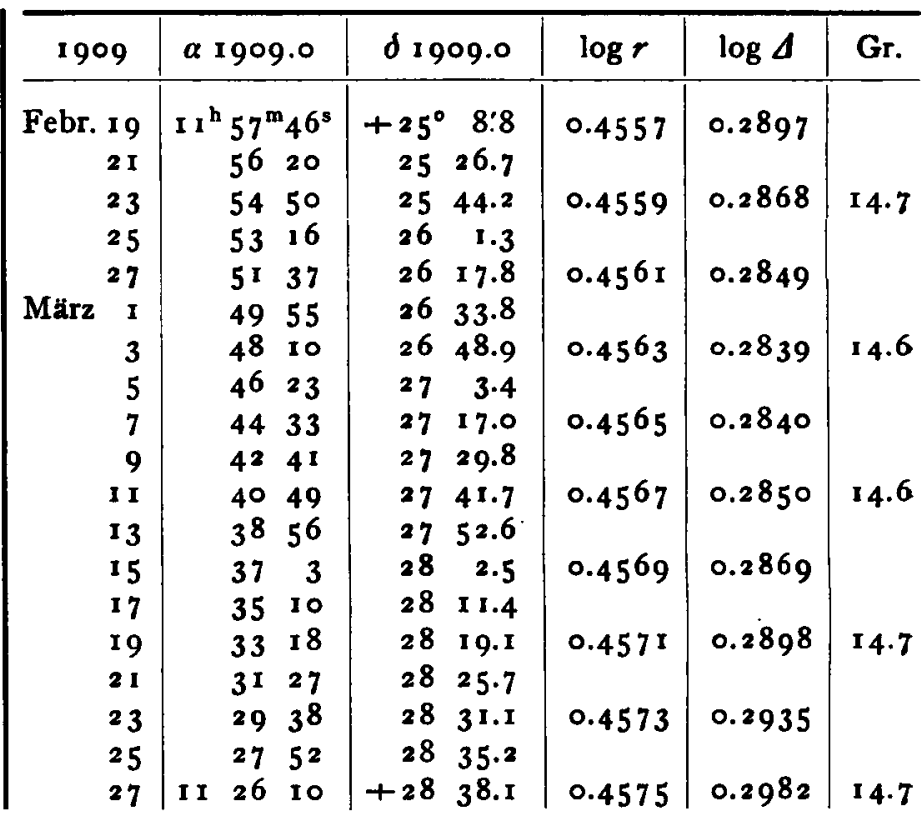

Opposition in RA.: März 14.
Triest, 1908 Nov. 10.

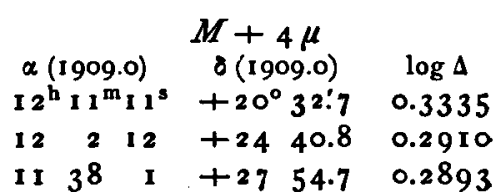

Dr. F. Hopfner. 